\title{
O RÁDIO EDUCATIVO NA PERCEPÇÃo DE PROFESSORES DA EDUCAÇÃo BÁSICA - O CASO RÁDIO escolar do Programa Mais educação
}

\author{
Edgard Patrício
}

\begin{abstract}
Resumo
As políticas públicas de literacia mediática ganham relevo frente às transformações dos modos de se fazer comunicação. E a efetividade dessas políticas, no âmbito da educação básica, pode esbarrar na receptividade dos professores. Este artigo analisa a percepção de professores da rede pública de ensino de Fortaleza (Brasil) sobre o rádio educativo e a orientação que eles adotam no desenvolvimento das atividades curriculares. A pesquisa foi realizada em 2014, em 21 escolas integradas ao Programa Mais Educação (PME). O PME, implantado em 2007 pelo Ministério da Educação, pretende desenvolver uma política de educação integral para as escolas. Uma das atividades ofertadas é a de rádio escolar, pelo macrocampo "Comunicação e Uso de Mídias". Foram realizadas 124 entrevistas, entre coordenadores do Mais Educação, professores e estudantes. As entrevistas foram realizadas a partir de um questionário de 63 questões. Para esse artigo, focamos na análise de 31 entrevistas com professores de escolas da rede pública que fizeram opção pela rádio escolar como atividade. Os resultados da análise apontam um baixo índice de participação dos professores no funcionamento da rádio escolar, uma percepção de aprendizagem ainda voltada apenas para o letramento e dificuldades na aproximação entre rádio escolar e sala de aula.
\end{abstract}

\section{Palavras-chave}

Políticas públicas; literacia mediática; participação; rádio escolar; professores

\section{INTRODUÇÃ̃O ${ }^{1}$}

A crescente complexificação dos suportes e processos comunicacionais, e sua inserção disseminada nas relações sociais, têm levado os países a trabalharem na implantação de políticas públicas que aproximem a escola da dimensão dos media. Em relação a Portugal e Brasil, dois documentos surgem como base da delimitação dessas políticas. Portugal lança o "Referencial de Educação para os Media para a Educação Pré-escolar, o Ensino Básico e o Ensino Secundário". O Brasil, por meio do Programa Mais Educação, dar a conhecer o "Caderno Pedagógico n 9", que estabelece as premissas do macrocampo Comunicação e uso de mídias no ambiente escolar.

Mas a aproximação entre as áreas da Comunicação e Educação não é algo recente. E o suporte utilizado para tal aproximação alterna-se de iniciativa a iniciativa, não importando que concepção de comunicação ou educação cada uma dessas iniciativas traga. Foi assim com Freinet (1974), no início do século XX, que trabalhava com a possibilidade do jornal escolar ser uma ferramenta de aprendizagem, na esteira das ideias trazidas

\footnotetext{
1 Este texto retoma um trabalho anteriormente desenvolvido pelo autor (Patrício, 2015).
} 
pelo movimento escolanovista (Monarcha, 2009), entre as quais estavam incluídas a valorização da técnica e a autonomia do estudante. Também foi assim com Edgard Roquete-Pinto (1926), que em 1923 fundou a Rádio Sociedade do Rio de Janeiro, com seu viés estritamente educativo (Prado, 2012). O mesmo aconteceu com o argentino Mário Kaplún (1999), que por meio do cassete-foro teimava em tornar dialógica uma comunicação que estava fadada ao fluxo unidirecional da informação. O mesmo princípio que animou Paulo Freire (1987) a defender o diálogo como estratégia educativa.

Ao longo da caminhada, alguns conceitos foram sendo construídos para designar essa aproximação entre Comunicação e Educação. Dois desses conceitos parecem aportar mais seguidores, no momento. No ambiente europeu, emerge o conceito de educação para os media. Na América Latina, sobressai o conceito de educomunicação. Nesses dois espaços geográficos, dois países vêm tentando articular algumas ações concretas que operacionalizem a aproximação entre Comunicação e Educação no contexto das práticas curriculares escolares. Portugal e Brasil vivenciam preocupações semelhantes quanto a essa questão.

Em Portugal, o aporte de estudos de instituições como a Organização das Nações Unidas para a Ciência e a Cultura (Unesco, 2011) embasam essa orientação. As pesquisas e as produções (Pereira, 2011; Pinto, 2003; Pinto, Pereira, Pereira \& Ferreira, 2011) do Instituto e do Centro de Ciências Sociais da Universidade do Minho (Braga, Portugal), também estruturam essa perspectiva. No Brasil, exemplos são os estudos e pesquisas protagonizados pelo Núcleo de Comunicação e Educação (NCE), da Universidade de São Paulo (Baccega, 2002; Soares, 1999, 2001) e por estudos e sistematizações da atuação de organizações não governamentais que trabalham na área da educomunicação (Sampaio, Patrício \& Campos, 2012; Vivarta, 2012).

Para além dos estudos e pesquisas de instituições acadêmicas ou da sociedade civil, os governos desses países também têm investido no aprofundamento da discussão sobre a aproximação entre comunicação e educação. Muitas vezes no bojo do lançamento de políticas públicas que buscam concretizar na aplicação do currículo escolar os conceitos trabalhados nesses estudos.

Aqui, nos voltamos especificamente para uma análise da iniciativa do governo brasileiro por meio do Programa Mais Educação, tendo como uma das ofertas de atividade o trabalho com a rádio escolar. São analisados os processos de participação e percepção de professores da rede pública de ensino de Fortaleza (Ceará-Brasil) em torno da operacionalização dessa atividade nas escolas.

\section{O Programa Mais Educação f a rádio escolar}

O Programa Mais Educação, ação desenvolvida pelo Ministério da Educação (MEC), pretende desenvolver uma política pública de educação integral para as escolas brasileiras. Implantado em 2007, a proposta de educação integral do Programa Mais Educação situa-se na trajetória de vários projetos semelhantes presentes em momentos da história do país. Criados pelos mais diversos educadores, esses projetos, embora 
pontuais e esporádicos, tentaram, a sua maneira, lidar com os desafios do acesso, permanência e aprendizado no contexto da educação do país.

Numa visão crítica do próprio Mais Educação, em sua apresentação, "esses programas buscaram a ampliação do tempo da jornada escolar, mas muitos não questionaram sobre a fragmentação do conhecimento e dos processos educativos e como isso pode interferir na permanência das crianças e dos jovens na escola" (Ministério da Educação, 2012, p. 9). Uma educação não somente de tempo integral, mas de proposta integrada e de ampliação de espaços da educação é o desafio a ser vencido pelo Mais Educação.

O Brasil caminhou, nas últimas décadas, para o acesso universal de crianças, adolescentes e jovens ao ensino fundamental. Mas as matrículas nesse nível de ensino superam a população residente. Esse dado revela que ainda há um represamento de crianças e adolescentes de faixa etária própria do ensino médio (15 a 17 anos) no ensino fundamental. Em 2011, para uma população residente de 29.264.015 na faixa etária de 6 a 14 anos, própria do ensino fundamental, foram efetivadas 30.358.640 matrículas (Ministério da Educação, 2013, p. 20). Em relação ao ensino médio, nem mesmo o acesso foi garantido. Em 2011, para uma população residente na faixa etária de 15 a 17 anos (própria do ensino médio) de 10.580 .060 adolescentes, as matrículas alcançaram apenas 8.400.689 dessa população (Ministério da Educação, 2013, p. 24). Em relação a dados qualitativos, em 2013 (Ministério da Educação, 2013b), apenas 89,3\% dos matriculados no ensino fundamental lograram aprovação. No ensino médio, o dado é ainda mais preocupante. Apenas $80,1 \%$ dos matriculados foram aprovados. Resultados que aumentam a distorção idade-série nos dois níveis de ensino, o que pressupõe maiores evasões escolares. Qual a qualidade da escola pública oferecida a nossas crianças, adolescentes e jovens? Ela consegue responder aos anseios desses segmentos da população? E como estruturar "sua resposta" a esse chamamento?

As estatísticas, explicitadas aqui, apontam para um distanciamento do papel que a instituição escolar representa, de fato, na vida de seus estudantes. Um grande desafio é justamente retomar o sentido que a escola tem para a vida e o sucesso pessoal de cada estudante. Sucesso no sentido de preenchimento das necessidades existenciais, culturais, acadêmicas, sociais e profissionais de cada um. Tornar-se necessária e desejada por todos - e exercer seu papel emancipatório central - exige da educação uma integralidade de proposta e uma capilaridade na realidade social e particular de cada estudante.

A educação integral, na definição do Programa Mais Educação (Ministério da Educação, 2012), propõe a formação mais completa possível do ser humano, considerando as particularidades das questões sociais do Brasil e alimentando-se de parcerias entre os ministérios e outras instâncias do Governo Federal. Abarca, dentre suas preocupações, requisitos que, de forma geral, não são contemplados em uma visão tradicional conteudista da educação e do espaço escolar, tais como o desenvolvimento de habilidades específicas, o diálogo entre os conhecimentos escolares e comunitários, a proteção e a garantia básica dos direitos de crianças, adolescentes e jovens e a preocupação com os temas da saúde pública.

Para isso, o Programa Mais Educação parte do princípio que as atividades curriculares e extracurriculares são partes de um único processo com um objetivo comum: 
a formação plena do educando, derrubando, assim, os limites e os vícios de um turno e contraturno escolares, ou seja, o Programa Mais Educação propõe repensar a estrutura seriada e compartimentada da escola. As atividades propostas nos cadernos do Mais Educação, segundo seu conteúdo, devem dialogar com as disciplinas acadêmicas e os conhecimentos juvenis e comunitários, para que o sentido de "integralidade" seja, realmente, exercido. Trata-se da discussão de uma nova ordem curricular na escola, um debate antigo na sociedade brasileira.

A partir do estabelecimento desses princípios, o Mais Educação defende que somente a integralidade de tempo não garante que a escola faça sentido àqueles para os quais ela foi criada: seus estudantes. E vários são os fatores que induzem a essa afirmação. A obsolescência de conteúdos, desconectados com a realidade do jovem, torna-se um empecilho à permanência do mesmo na sala de aula. Para acompanhar as demandas sociais de cada estudante, o Programa Mais Educação propõe, também, o rompimento com o enclaustramento criado pelo espaço escolar, ou seja, "derrubar os muros da escola", pelo menos na esfera do conhecimento.

É por isso que o Programa Mais Educação aposta no conceito da territorialidade. A territorializacão da escola - ampliando seus espaços físicos, para além de seus muros e de suas salas de aula, e abarcando saberes, para além de seus livros, tornaria a proposta da educação potencialmente conectada com demandas reais e cotidianas do público ao qual a escola serve. A escola passaria, assim, a ser parte da comunidade na qual está inserida, de forma a ser respeitada e considerada por seus membros, não mais um organismo meramente burocrático que, quase que por acaso, faz parte daquela paisagem.

\section{A OFERTA}

A oferta de atividades do Programa Mais Educação é dividida em macrocampos. Um dos macrocampos é o Comunicação e Uso de Mídias. Nesse macrocampo são oferecidas às escolas públicas atividades relacionadas ao jornal escolar, rádio escolar, história em quadrinhos, fotografia e vídeo. Dados fornecidos ao autor pela Secretaria de Educação Básica, do Ministério da Educação, revelam que em 2010, foram atendidas 9.995 escolas, alcançando três milhões de estudantes. Dessas, 3.911 optaram pelo macrocampo Comunicação e Uso de Mídias. Nesse universo, 2.218 escolas fizeram opção pela rádio escolar. Destaque para o estado do Ceará. De suas 333 escolas integradas ao Mais Educação até 2010 e que trabalham com o macrocampo Comunicação e Uso de Mídias, 246 optaram pela rádio escolar.

O Ceará só perde para o Rio de Janeiro na opção por rádio escolar. No Rio, 375 escolas fizeram essa opção. Há que se levar em consideração que o número de escolas do Rio de Janeiro integradas ao Mais Educação até 2010, no macrocampo Comunicação e Uso de Mídias (658), é praticamente o dobro do número de escolas do Ceará (333).

No Ceará, as 246 escolas que optaram pela rádio escolar até 2010 congregam 34.480 estudantes. São 71 escolas estaduais e 175 municipais. Dados incluindo a adesão realizada pelas escolas em 2011 apontaram Fortaleza, capital do estado, com 108 escolas 
optantes pelas rádios escolares, sendo 61 da rede pública municipal e 47 da rede pública estadual, com a participação de mais de 15 mil estudantes. Dados atualizados em 2012, fornecidos ao autor pela Secretaria Municipal de Educação de Fortaleza, contabilizam 48 escolas, da rede pública municipal, com opção pela rádio escolar e 28.957 estudantes alcançados. O dado mais recente sobre a opção rádio escolar pelas escolas dá conta de que 210.045 estudantes fizeram opção pela rádio escolar em todo o Brasil, em 2012 (Ministério da Educação, 2013, p. 23).

O “Caderno Pedagógico 9" (Ministério da Educação, 2012), que trata do macrocampo Comunicação e Uso das Mídias pelo Programa Mais Educação, parte de Umberto Eco (1991) para justificar a importância da discussão sobre o campo dentro da proposta de educação integral do MEC. E destaca o conceito de "idade mídia", do autor referenciado, como atestador da importância que a comunicação tem no mundo atual. Também tornam explícita sua inspiração em Paulo Freire ao falar da aproximação entre as duas áreas, Comunicação e Educação (Freire, 1979). "Ora, se a escola tem no âmago da sua existência a construção da autonomia dos educandos, como seria possível realizar essa tarefa sem considerar a comunicação e seu papel na sociedade hoje?" (Ministério da Educação, 2012, p. 9). E acaba por assumir o termo Educomunicação como a nova área acadêmica que alia as duas áreas antes específicas, a Educação e a Comunicação. Nesse caso, aproximam-se do pensamento de Martin-Barbero (2008), a partir de uma visão culturalista da realidade.

E como se daria essa aproximação da Educação da Comunicação? Ou, mais especificamente, a aproximação entre a escola e a Comunicação? O "Caderno Pedagógico n' 9" (Ministério da Educação, 2012) aponta essa aproximação pelo viés dos destinatários da escola, quando indica que as mídias "estão na origem de uma nova cultura, orientada para o futuro, na qual adolescentes e jovens têm como referência principal seus pares; essa mutação está sendo aprofundada pela internet" (Ministério da Educação, 2012, p. 15). E onde ficaria o adulto nessa história? Pareceria "à primeira vista, que o adulto perdeu influência na formação dos jovens, mas não é assim. A comunicação de massa gerou a nova cultura e, ao mesmo tempo, a significou, normalizando-a dentro das necessidades do momento atual do mercado capitalista" (Ministério da Educação, 2012, p. 15).

A escola estaria, assim, entre as instituições adultas que teriam perdido força quanto sua ação educativa. E o "Caderno Pedagógico n 9" aponta como a recuperação desse lugar anteriormente ocupado pode se dar a partir de outra instituição adulta, no caso a mídia. Mas a partir de uma visão crítica da nova instituição.

Decorre disso que, para a escola recuperar o seu papel, deveria, em primeiro lugar, lutar por sua própria legitimidade perante crianças e jovens. Colocamos aqui, como tese, que ela não pode recuperar essa legitimidade se não desvendar, através da crítica, a mistificação proposta pelo mundo da comunicação-mercado. Essa crítica gera a possibilidade de se criar uma cumplicidade com os mais jovens, valorizando e promovendo a busca da autonomia como uma aventura existencial íntima, do pensamento e do 
conhecimento, e não como uma proposta condicionada, subliminarmente, pela lógica mercantil. (Ministério da Educação, 2012, p. 15)

A recuperação do papel da escola estaria, então, ainda para o "Caderno Pedagógico n 9" (Ministério da Educação, 2012), relacionada à capacidade que tiver de converter-se num espaço privilegiado para garantir às novas gerações os conhecimentos e as habilidades indispensáveis, para que se comuniquem com autonomia e autenticidade. Seria a partir de uma "pedagogia problematizadora" que a leitura da mídia será mais eficiente, caso os jovens tenham garantida a capacidade de analisar suas próprias formas de comunicação e as maneiras de se comunicar adotadas e privilegiadas pela escola.

O pesquisador brasileiro Ismar Soares (2001) é o autor reconhecido pelo "Caderno Pedagógico n 9" ao tratar da Comunicação e Uso de Mídias na escola, utilizando o termo Educomunicação. O novo campo absorveria seus fundamentos dos tradicionais campos da educação, da comunicação e de outros campos das ciências sociais, superando, desta forma, as "barreiras epistemológicas impostas pela visão iluminista e funcionalista de relações sociais que mantêm os tradicionais campos do saber isolados e incomunicáveis" (Ministério da Educação, 2012, p. 16). O novo campo aconteceria a partir de

ações conjuntas em diferentes áreas, ganhando a dimensão de um movimento que caminha sintonizado em torno de uma ideia básica: possibilitar o conhecimento sobre a sociedade midiática, mediante o exercício do uso de seus recursos, sempre numa perspectiva participativa e integradora dos interesses da vida na comunidade. (Ministério da Educação, 2012, p. 16)

As diversas mídias, para o "Caderno Pedagógico n 9" (Ministério da Educação, 2012 , p. 18), teriam o potencial de se tornarem parte de um sistema de comunicação entre estudantes, professores, diretores e comunidade escolar. Assim, carregariam o potencial de instigar diálogos para a construção de um projeto político-pedagógico rico e alinhado às características de uma escola que tenha importância na vida de seus estudantes e da comunidade. Mas o caminho para chegar a essa realidade passaria pelo enfrentamento de alguns desafios.

A compreensão do "Caderno Pedagógico n 9 " sobre o uso das mídias na escola passa por uma visão interdisciplinar desse processo. Ele aponta que, embora, "não tenha o objetivo de solucionar todas as questões da educação brasileira, o Mais Educação, por meio da Comunicação e Uso de Mídias, é um instrumento importante de flexibilização do currículo e de capilarização de uma proposta interdisciplinar" (Ministério da Educação, 2012, p. 19). Uma das primeiras percepções na produção de comunicação é a de que um jornal, vídeo, rádio, fotografia e quadrinhos são, por natureza, produtos interdisciplinares, ou seja, exigem a aplicação de múltiplos saberes acadêmicos na sua elaboração. A produção em comunicação é entendida como "uma prática estudantil/ escolar, que respeita a autonomia dos estudantes e que deve envolver as mais diversas disciplinas" (Ministério da Educação, 2012, p. 19).

Outra dimensão do interdisciplinar estaria relacionada aos diversos saberes que entrariam na composição dessa nova aprendizagem. Para o "Caderno Pedagógico n 9" (Ministério da Educação, 2012), os 
saberes comunitários e estudantis têm, também, espaço nessa construção. As redes que constituem esses saberes (...) são fundamentais, inclusive, como forma de o educando reconhecer-se no processo. A agenda da criança e do jovem deve ser a linha mestra do jornal, revista, rádio ou vídeo produzido; o potencial da comunidade torna-se visível e ativo no conteúdo proposto e discutido. (Ministério da Educação, 2012, p. 19)

Além disso,

A integração dos saberes acadêmicos, comunitários e estudantis facilita, para que a escola torne-se articuladora de uma comunidade de aprendizagem, isto é "uma comunidade humana organizada que constrói um projeto educativo e cultural próprio para educar a si própria, suas crianças, seus jovens e adultos". (Ministério da Educação, 2012, p. 19)

O papel social da leitura e escrita é o ponto de partida para que o "Caderno Pedagógico $n^{\circ}$ 9" evidencie a importância da ressignificação dos espaços sociais onde as pessoas exercem sua cidadania. A garantia de "acesso aos veículos de comunicação, ao domínio de diferentes linguagens e à produção de comunicação, como forma de participação democrática são elementos fundamentais do programa do MEC e, também, atividades centrais das práticas educomunicativas" (Ministério da Educação, 2012, pp. 19-20). O exercício da leitura crítica da mídia de massa seria "um dos pressupostos, para que o jornal, revista, quadrinhos, vídeo ou rádio produzidos por crianças, adolescentes e jovens tenham de fato um caráter autêntico e inovador nos programas de Comunicação e Uso de Mídias" (Ministério da Educação, 2012, pp. 19-20). Seria preciso antes de qualquer esforço para produzir comunicação, "conhecer e analisar o sistema midiático de massa que, hoje, é ainda dominante. Isso significa entender, profundamente, as relações comerciais dos veículos e o papel importante que eles exercem na construção de valores pessoais e sociais" (Ministério da Educação, 2012, pp. 19-20).

Mas a dimensão da proposta do MEC para o uso das mídias pela escola, consubstanciada no "Caderno Pedagógico n 9 ", não estaria restrita à recepção crítica da comunicação. O "Caderno Pedagógico n 9 " aponta para uma etapa seguinte, de produção da comunicação.

Após a leitura e análise das diferentes mídias, a ênfase da Educomunicação é a produção e, sobretudo, a veiculação, do material feito pelos estudantes. Trata-se de uma comunicação autêntica dos educandos. Nos jornais, fanzines, rádios, vídeos ou quadrinhos, o estudante é instigado a produzir uma comunicação que faça sentido a ele e sua comunidade; temas que gerem discussão e pautem debates sobre soluções e problemas comunitários ou relativos às questões da juventude em si, como a sexualidade e outros existenciais. (Ministério da Educação, 2012, p. 20)

Seria uma primeira aproximação do "Caderno Pedagógico n ${ }^{\circ} 9$ " ao pensamento de Celestine Freinet (1974) e à Escola Nova, movimento que propõe aos alunos atividades 
diversas - intelectuais, artísticas, físicas, trabalhos manuais - prefigurando o que, hoje, chamamos de educação integral. Dentre essas atividades, a utilização dos dispositivos de impressão tipográfica, dando início à produção de impressos escolares. Para o "Caderno Pedagógico n 9", a

(...) importância de Freinet na história das mídias escolares não está em ter sido um precursor - não o foi, como vimos - mas no fato de ter feito do jornal um ponto de "concentração" e a síntese de uma proposta pedagógica inspirada nos princípios da Escola Nova. Não há em Freinet o menor traço de uma perspectiva instrumental ou funcionalista do jornal (mídia) escolar, que foque em algum aspecto parcial, como o rendimento escolar ou o domínio de tecnologias, por exemplo. Sua visão parte de uma concepção integral da criança e conclui na formulação de um pensamento que pode ser considerado como precursor de uma visão integral da educação. $O$ texto que segue se inspira, largamente, em Freinet. (Ministério da Educação, 2012, pp. 24-25)

Por último, cabe destacar, ainda, a visão do "Caderno Pedagógico n 9" em torno da função social da leitura e da escrita nos processos de aproximação entre Educação e Comunicação no ambiente escolar. O uso da língua e da expressão, no processo, seria "fundamental, para que a mensagem seja compreendida pelo receptor (público-alvo da mídia em questão) e o produto de comunicação seja, de fato, eficiente. Trata-se de um exercício constante de pesquisa de linguagem e de uso social da escrita" (Ministério da Educação, 2012, p. 20). A preocupação 'em ser compreendido' faria da comunicação uma "prática de uso cotidiano da língua e do jornal produzido, sendo uma ferramenta importante de cidadania" (Ministério da Educação, 2012, p. 20). Os educandos seriam levados a perceber que é "a partir da mudança e leitura de mundo locais, que são construídas as leituras e as mudanças globais, e que é possível elaborar um novo, transformador e autêntico tipo de comunicação" (Ministério da Educação, 2012, p. 20).

Em suma, na base da proposta do Programa Mais Educação, em relação ao macrocampo Comunicação e Uso de Mídias, estão as ideias de que vivemos numa 'idade mídia', daí a importância do macrocampo; que os projetos que as escolas possam implementar na área devem privilegiar a realidade dos educandos; mais que isso, devem ser construídos levando-se em consideração a autonomia dos estudantes; que devem ser inseridos a partir de uma proposta crítica da comunicação que se pratica hoje; que as propostas implementadas no âmbito do macrocampo devem possibilitar os diálogos para o desenvolvimento de um projeto pedagógico rico; que essas propostas partam de uma visão que envolva as diversas disciplinas; na perspectiva de aproximação entre saberes escolares e comunitários; e que evidenciem a função social da leitura e da escrita.

Como os professores dessas escolas interpretam essas possibilidades? E como constroem, na prática, essa outra comunicação? 


\section{ConteXtualizando a PesQuisa}

\section{A rotina do Programa Mais Educação nas escolas}

A cada ano, as escolas fazem a opção pelas atividades que querem desenvolver em torno do Programa. Em média, a escola "pode" escolher entre cinco e seis atividades, do conjunto de atividades que compõem todos os macrocampos do Mais Educação. São 10 macrocampos à disposição das escolas: i. Acompanhamento Pedagógico, ii. Educação Ambiental, iii. Esporte e Lazer, iv. Direitos Humanos em Educação, v. Cultura e Artes, vi. Cultura Digital, vii. Promoção da Saúde, viii. Comunicação e Uso de Mídias, ix. Investigação no Campo das Ciências da Natureza, x. Educação Econômica. Esses macrocampos oferecem 62 diferentes atividades aos estudantes (Ministério da Educação, 2011). O MEC também orienta a seleção dessas atividades, daí o "pode" estar entre aspas. Dessas cinco ou seis atividades, uma, necessariamente, tem que ser a de reforço pedagógico, do macrocampo Acompanhamento Pedagógico, de caráter obrigatório para as escolas participantes. E em 2013, o MEC não disponibilizou o macrocampo Comunicação e Uso de Mídias para as escolas rurais. Apenas as escolas urbanas puderam fazer a opção por alguma de suas atividades.

Feitas as opções pelas atividades, as escolas recebem o apoio necessário do MEC para desenvolvê-las. Em relação ao macrocampo Comunicação e Uso de Mídias, na opção rádio escolar, o apoio alterna-se entre o envio de um kit de equipamentos para escola utilizar ou a remessa de recursos financeiros para que a própria escola adquira os equipamentos. No ano em que o MEC fica responsável pelo envio dos próprios equipamentos, as escolas chegam a esperar um ano para a efetiva remessa. Como a opção das atividades é anual, em algumas escolas os equipamentos chegam sem que a escola tenha mais a opção rádio escolar entre suas atividades do Mais Educação, o que gera descontinuidade de atividades. $O$ atraso na chegada dos equipamentos também desestimula a participação dos estudantes e professores, que veem suas expectativas não atendidas ao longo daquele ano.

O MEC, no caso da rádio escolar, também apoia a escola fazendo um repasse de recursos para que ela possa contar com um monitor para acompanhar as turmas formadas. Há uma indicação, mas não uma obrigatoriedade, desse monitor ter formação específica sobre rádio. A remuneração desse monitor é de $\mathrm{R} \$ 80,00$ reais por turma formada. Face à baixa remuneração, ocorre uma rotatividade intensa desses colaboradores. Isso quando a escola consegue atrair algum colaborador para realizar esse trabalho.

Com os equipamentos e monitor disponíveis, inicia-se o processo de desenvolvimento das atividades. Um dos problemas verificados, nessa fase, é o de falta de autonomia dos estudantes na adesão às atividades propostas. O mesmo estudante que faz a opção, por exemplo, por rádio escolar, tem, obrigatoriamente, que participar de todas as outras atividades selecionadas pela escola para aquele ano. A atividade de reforço pedagógico é diária. Cada atividade toma, em média, 90 minutos das três horas diárias dedicadas ao Mais Educação na escola, no contraturno escolar. Tomando-se por base cinco atividades selecionadas mais o reforço pedagógico, de caráter obrigatório, a cada dia o estudante participa do reforço pedagógico mais uma atividade. Em razão disso, se 
a escola fizer a opção por rádio escolar o trabalho com essa atividade vai se resumir a 90 minutos semanais, seis horas mensais, o que prejudica qualquer processo formativo que venha a se desenvolver, de caráter mais sistemático.

\section{A SELEÇÃo do CONJUNTO de DADOS DA PESQUisa}

Para a pesquisa, foram selecionadas 21 escolas pertencentes às redes públicas de Fortaleza (estadual e municipal). O critério de seleção das escolas foi baseado na vinculação com o Programa Mais Educação, na opção pela atividade Rádio Escolar e, mais ainda, que em algum momento a rádio escolar tivesse efetivamente funcionado -em muitas escolas os equipamentos foram recebidos e não foram sequer instalados. Foram elaborados questionários específicos para diretores, coordenadores das atividades do Programa Mais Educação, professores de sala de aula e estudantes. O número de entrevistados variou de escola para escola e entre os segmentos, de acordo com a disponibilidade demonstrada pela comunidade escolar para participar da pesquisa. Em relação a professores e estudantes, fizemos uma divisão entre aqueles que participaram da atividade de rádio escolar e aqueles que não participaram - como nosso intuito era ter uma percepção da compreensão da relação entre rádio e aprendizagem, a partir da proposta do Comunicação e Uso de Mídias, essa separação nos pareceu apropriada, levando-se em consideração quem é apenas ouvinte da rádio escolar e quem é participante ativo do processo de produção da comunicação veiculada pela rádio escolar.

Especificamente para esse artigo, selecionamos 31 questionários de professores entrevistados, entre aqueles que tomaram parte, em algum momento, das atividades da rádio escolar e os que não tomaram parte. Cabe salientar que a participação nas atividades da rádio escolar pode ter acontecido em momentos anteriores ao da realização da pesquisa, uma feita que entre a opção pela atividade e o desenvolvimento efetivo das atividades pode decorrer um intervalo de tempo que pode chegar a 18 meses, dependendo da disponibilidade dos equipamentos, incluída sua instalação na escola. O número de professores entrevistados variou de escola a escola, a partir da disponibilidade encontrada pelos entrevistadores.

Os professores responderam a um questionário de 63 perguntas, com questões abertas ou de múltiplas escolhas, dividido em duas partes: i. cenário do Programa Mais Educação, incluindo indagações sobre o processo de implantação do Programa na escola; e ii. cenário Comunicação e Uso de Mídias e opção rádio escolar, tratando do processo de opção da atividade rádio escolar e sua implementação na escola. Devido ao espaço disponível nesse artigo, concentramos nossa análise nos dados de um conjunto de perguntas que nos parece chave nessa discussão, e que evidencia a qualidade da relação entre professores e atividades da rádio escolar: a participação dos professores nas atividades da rádio escolar; a responsabilidade pela definição da programação da rádio escolar, incluindo a inserção ou retirada de programas do ar; a percepção dos professores sobre a dimensão da aprendizagem vinculada às atividades da rádio escolar; e a compreensão dos professores sobre o conceito de rádio educativo. Cabe salientar que 
alguns escores de algumas perguntas superam o número de 31 entrevistas realizadas. Isso se verifica pelo fato de que em algumas questões era possível a seleção de mais de uma alternativa (múltiplas escolhas). Como exemplo, a pergunta que indagava quem era o responsável por definir a programação da rádio escolar.

\section{As PERCEPÇÕeS dOS PROFESSORES do MAIS EdUCAÇÃo SOBRE O RÁdIO EDUCATIVO}

O Programa Mais Educação, em sua proposta pedagógica de orientação à execução do macrocampo Comunicação e Uso de Mídias, destaca que as propostas implementadas devem possibilitar os diálogos para o desenvolvimento de um projeto pedagógico rico; que essas propostas partam de uma visão que envolva as diversas disciplinas; sobretudo, que esses projetos possam desenvolver diálogos no âmbito da comunidade escolar, o que atestaria a importância entre Comunicação e Educação. Ou seja, não haveria, a princípio, êxito na iniciativa sem a efetiva participação do professorado nas atividades. Mas isso não está sendo vivenciado no conjunto de escolas alcançadas pela pesquisa.

A ausência dos professores nas atividades da rádio escolar é atestada pelos dados. Dos 31 professores entrevistados, apenas cinco $(16,1 \%)$ tomaram parte, em algum momento, das atividades da rádio escolar e $26(83,9 \%)$ não tomaram parte. Esse resultado é reforçado na sistematização de outro dado da pesquisa. Indagou-se quem definia a programação da rádio escolar, e quem era responsável por tirar um programa do ar. Em relação à definição da programação, os professores afirmaram uma participação mais autônoma dos estudantes, o que vem ao encontro da orientação do macrocampo. Das respostas colhidas sobre esse aspecto, o total de 14 (33,3\%) assinalou que eram os estudantes que decidiam a programação da rádio escolar. Em seguida seriam os monitores, com nove afirmativas $(21,4 \%)$. Em terceira posição, eram os próprios coordenadores do Mais Educação quem decidiam o que veicular nas rádios escolares, com oito respostas afirmativas (19\%). Já os professores foram reconhecidos como participantes da definição da programação da rádio escolar por apenas três $(7,14 \%)$ de seus pares.

Se a participação dos professores era pífia na definição da programação da rádio escolar, essa orientação quase dobra quando de outro processo de gestão dessa atividade do Mais Educação. Falamos da tomada de decisão em relação a retirar um programa do ar da rádio escolar. Das 52 indicações sobre quem seria o responsável por isso, 19 $(37,2 \%)$ sugeriram ser o diretor ou o núcleo gestor da escola. Outras $15(27,4 \%)$ afirmações indicaram o coordenador do Mais Educação. Somente em seguida vem o professor, com sete $(13,7 \%)$ das indicações, um aumento percentualmente considerável em relação ao item anterior, mas ainda pouco expressivo no conjunto dos dados. Os estudantes aparecem com quatro indicações (7,8\%). Mais que a baixa participação dos professores nos processos de gestão da rádio escolar, percebe-se um centralismo nesse âmbito, o que aponta para a incapacidade do macrocampo Comunicação e Uso de Mídias estabelecer um diálogo efetivo entre as diversas disciplinas do currículo e dentro da própria comunidade escolar. 
A participação mencionada do professor na tomada de decisão (quem define a programação, quem tira um programa do ar ainda pode estar mascarada pelo fato do coordenador do Mais Educação também ser um professor, mas que coordena TODAS as atividades do Mais Educação na escola, o que acaba por inviabilizar sua atuação como professor de uma maneira mais efetiva junto à rádio escolar. Vê-se que a perspectiva da colaboração recíproca entre professor e estudante, preconizada pela proposta pedagógica do Comunicação e Uso de Mídias, também está distante de se realizar.

\section{A PERCEPÇÃo DA APRENDIZAGEM}

Em torno da percepção do rádio educativo, duas indagações do instrumental de pesquisa foram feitas. A primeira, "Você acredita que a Radioescola ajuda na aprendizagem dos estudantes?"; e a segunda, "O que é o rádio educativo pra você?". Ambas as perguntas de caráter aberto. Aqui, especificamente, foram sistematizadas as respostas distinguindo os professores participantes dos não participantes das atividades da rádio escolar - na medida em que o próprio envolvimento e possíveis processos formativos levados a cabo pelo professor participante, de alguma maneira, pudesse ter reorientado essa percepção.

Entre os cinco professores que afirmaram ter participado em algum momento das atividades da rádio escolar, apenas dois afirmaram que esse ambiente pode favorecer, em muito, a aprendizagem. Outros dois indicaram não saber avaliar essa perspectiva e um deles se posicionou como se a rádio escolar colaborasse pouco para a aprendizagem dos estudantes. Uma das justificativas para a alta possibilidade de aprendizagem seria o fato de que "quando tem uma atividade extra, como a rádio, teatro, sarau, ajuda no processo de aprendizagem, convívio. Chamam muito atenção dos estudantes". Essa afirmação pode indicar uma percepção de distanciamento da aprendizagem da atividade da rádio escolar com qualquer vínculo à sala de aula - embora um maior número de respondentes configurasse uma maior segurança de interpretação.

Mas o que salta aos olhos é a afirmação de um dos professores que participou das atividades da rádio escolar e que considera a aprendizagem dos estudantes algo bem efetivo. Por quê? Simplesmente porque "eles são obrigados a escrever e a falar". Exemplo de que a orientação pedagógica do macrocampo Comunicação e Uso de Mídias, quanto a indicação do diálogo como estratégia de desenvolvimento das atividades, pode não ser tão efetiva entre os professores.

Já entre aqueles professores que observam a rádio escolar de longe, que nunca participaram de suas atividades, a expectativa em relação à melhoria da aprendizagem dos estudantes é considerável. Dos 26 entrevistados, $12(46,1 \%)$ acreditam que essa melhoria pode ser bem efetiva. Do outro lado, quatro $(15,3 \%)$ indicam que não tem nenhuma vinculação entre a rádio escolar e o processo de aprendizagem e sete $(26,9 \%)$ assinalaram não saberem opinar sobre a indagação.

Sobre as justificativas para acreditar-se na relação entre rádio escolar e aprendizagem, um conjunto de respostas aponta para uma das preocupações do Mais Educação, 
em relação a aprendizagem da leitura e escrita como viés importante da percepção social do estudante. As falas dos professores apontam essa relação, quando inquiridos sobre a aprendizagem: "A parte de leitura e escrita é desenvolvida", "Melhora a escrita, a fala, capacidade de comunicação", "Motiva os alunos a produzir, buscar conhecimento, se interessar pelos estudos e ter mais consciência de seu papel como estudante no ambiente escolar", "Se sentem mais inseridos na sociedade, melhorar autoestima" foram algumas das respostas sistematizadas.

A aproximação dos interesses dos estudantes, outra perspectiva apontada pela orientação pedagógica do Mais Educação, encontra acolhida entre os professores para justificar uma possível melhoria da aprendizagem dos estudantes quando vinculados às atividades da rádio escolar. Entre as respostas, "É uma coisa que eles gostam, nova para eles", "Quando eles ouviam recadinhos se interessavam em escrever recadinhos e levavam isso pra sala de aula, pois, como o recadinho seria lido, eles queriam escrever direito e pediam ajuda às professoras", "Eles ouviam música que eles gostavam e levavam os seus recados". Entretanto, um dos professores chamou atenção para a tênue fronteira entre aproximação de interesses de estudantes e uma utilização restrita do potencial da rádio escolar. Crítico em relação à possível aprendizagem que estaria ocorrendo em sua escola, ele qualifica a utilização da rádio escolar como pouca. "Ela só tem a função de entretenimento", foi o que afirmou.

Ainda importante salientar outra perspectiva que pode, inclusive, ter influenciado a não participação dos professores nas atividades da rádio escolar, e que repercute também na análise da efetividade da aprendizagem representada pela atividade na escola. Inicialmente, o reconhecimento da própria ausência do professor, e consequentemente o distanciamento da rádio escolar da sala de aula-um professor se refere à "falta de interação entre professores e radioescola para que esta seja usada como uma mídia para incentivar a aprendizagem dos alunos"; ou a ausência de formação do professor para assumir tal atividade -conforme o relato de outro professor, que afirma "Como foi muito pouco tempo, não é possível avaliar se houve aprendizado, pois não havia preparo ou elaboração da utilização da rádio junto com os professores"; e mesmo a deficiências de gestão -segundo depoimento de outro professor, segundo o qual "Poderia ter. Não tem devido à falta de planejamento e de interação com outras partes da escola”.

\section{A PERCEPÇÃo SOBRE O RÁDIO EDUCATIVO}

A percepção sobre o rádio educativo entre os professores reforça a ideia do distanciamento sobre o vínculo da rádio escolar com a sala de aula. Não menos importante, mas mesmo assim restrito, o que sobressai nas respostas, entre os professores participantes e não participantes da rádio escolar, é a dimensão mais ampla do referencial educativo. Poderíamos estabelecer três níveis nessas percepções, alicerçadas em falas dos professores respondentes à pesquisa.

O primeiro nível é representado pelos professores que veem ainda alguma aproximação entre o educativo e o escolar, a partir do ensino. Essa percepção é reforçada 
por seus depoimentos: "Um momento no qual o aluno pode ler um texto produzido em sala, mostrar seus gostos musicais. Tudo isso é aprendizado. Pode fazer comunicados da escola. A música em si também é uma coisa importante para o ser humano"; "É um meio de comunicação que ajuda a divulgar informações de interesse dos alunos, mais da área da educação (cursos e outras informações relativas à aprendizagem)"; "Transmite conhecimentos contextualizados na sala de aula e no dia-a-dia através da rádio".

Outro conjunto de respostas, representativo do segundo nível da relação entre o educativo e o escolar, amplia a percepção da aprendizagem. Na compreensão de professores depoentes que incorporam essa percepção ampliada de aprendizagem, o rádio educativo "fala de educação de um modo geral: pesquisa, resultado de um problema que a escola tenha, questões relativas à educação como um todo, atender algumas ansiedades dos alunos"; "Um movimento que vai ajudar no desenvolvimento dos jovens, ensiná-los a partilhar o seu conhecimento e se enriquecerem nessa partilha"; "É um recurso a mais que você pode utilizar para melhorar a aprendizagem dos alunos. É um recurso que eles gostam, uma forma de os alunos serem responsáveis pela aprendizagem deles".

Por fim, num terceiro nível, da relação entre o educativo e o escolar, o rádio educativo é percebido dentro de uma compreensão bastante ampla da aprendizagem, com pouca vinculação com o ensino e a sala de aula. $\mathrm{Na}$ opinião dos professores que incorporam essa percepção, o rádio educativo seria "Uma possibilidade de integração do aluno com a sociedade, com a comunicação. Uma oportunidade de perceber que não somo tão individuais, tão formados, mas temos a necessidade de viver o outro, informar o outro, capacitar e fazer algo pelo outro"; "É quando você faz com que o aluno perceba não só o seu mundo, mas também veja o mundo em volta dele. Todas as condições financeiras, sociais, e que eles saibam encontrar assuntos que eles possam estar interagindo, lendo, se informando, comunicando, eu acho que isso é rádio educativa"; "Deve tratar de assuntos relativos à cidadania, ética, meio ambiente, no sentido de educar o cidadão".

\section{MAIS ALgUMAS CONSIDERAÇõES}

Para a construção de uma proposta de rádio educativo que avance ao encontro dos princípios postos pelo MEC, é fundamental, antes de tudo, uma percepção crítica do modelo e conteúdo da comunicação mais utilizada em nossa realidade. Seria até defensável afirmar que, ao contrário do que afirma o MEC, não seria necessária a postulação de uma visão em etapas quanto ao fluxo de primeiro se perceber criticamente a comunicação para depois se produzir uma comunicação autônoma, ou educativa. Mas essa percepção crítica da comunicação está ausente da fala dos professores, mesmo considerando-se suas boas intenções. E são esses aspectos contraditórios que, se encaramos o conflito como algo positivo, podem render bons diálogos, no intuito de reconhecer as distâncias entre o pensar e o fazer. Uma dessas distâncias, são as deficiências, ou mesmo ausências, dos processos formativos junto aos professores que participam das atividades específicas do macrocampo Comunicação e Uso de Mídias. 
Outra consideração possível é sobre a percepção ampla que os professores têm do rádio educativo. Seria essa percepção vinculada a uma interpretação negativa da sala de aula, ou mesmo da escola? A notada ausência do professor dos processos que envolvem a rádio escolar poderia estar fortalecendo essa compreensão? Com a participação efetiva dos professores, nas atividades da rádio escolar, poderia se esperar uma reorientação dessa percepção? Ou um aprofundamento? Como trabalhar a percepção do rádio educativo e da aprendizagem na perspectiva de articulação entre os âmbitos micro e macro desses processos?

\section{REFERÊNCIAS BIBLIOGRÁFICAS}

Baccega, M. A. (Ed.) (2002). Gestão de processos comunicionais. São Paulo: Atlas.

Eco, U. (1991). O superhomem de massa. S. Paulo: Perspectiva.

Freinet, C. (1974). O jornal escolar. Lisboa. Editorial Estampa.

Freire, P. (1979). Educação como prática da liberdade. Rio de Janeiro: Paz e Terra.

Freire, P. (1987). Pedagogia do oprimido. Rio de Janeiro: Paz e Terra.

Kaplún, M. (1999). Producción de programas de rádio. El guión e la realización. Quito-Equador: Ediciones CIESPAL.

Martin-Barbero, J. (2008). Dos meios às mediações. Rio de Janeiro: Editora UFRJ.

Monarcha, C. (2009). Brasil arcaico, escola nova. São Paulo: Unesp.

Pereira, L. (2011). Concepções de literacia digital nas políticas públicas - estudo a partir do Plano Tecnológico da Educação. Tese de doutoramento. Universidade do Minho, Braga, Portugal. Retirado de https:// repositorium.sdum.uminho.pt/bitstream/1822/19825/1/Lu\%C3\%ADs\%20Miguel\%20Gonçalves\%2O Pereira.pdf.

Pinto, M. (2003). Correntes da educação para os media em Portugal: retrospectiva e horizontes em tempos de mudança. Revista Iberoamericana de Educación, 32, s/p.

Pinto, M., Pereira, S., Pereira, L. \& Ferreira, T. (2011). Educação para os media em Portugal: experiências, actores e contextos. Lisboa: Entidade Reguladora para a Comunicação Social.

Prado, M. (2012). História do rádio no Brasil. Livros de Safra.

Roquette-Pinto, E. (1926). Rádio e educação do Brasil. Revista Electron, 1(6), s/p.

Sampaio, A. L., Patrício, E. \& Campos, T. (Eds.) (2012). Sintonia Infância: uma trajetória de comunicação para a garantia dos direitos infantojuvenis. Fortaleza: Gráfica LCR.

Soares, I. (1999). Comunicação/Educação: a emergência de um novo campo e o perfil dos profissionais. Contato, Revista Brasileira de Comunicação, Arte e Educação. 1(2), 5-75.

Soares, I. (2001). Caminhos da educomunicação. São Paulo: Editora Salesiana.

Unesco (2011). Media and information literacy: curriculum for teachers, Paris: Unesco. 
Vivarta, V. (Ed.) (2000). Os jovens na mídia. Pesquisa ANDI/IAS/Unesco. Brasília, ANDI Agência de Notícias dos Direitos da Infância: Instituto Airton Senna/Unesco. Série Mobilização Social.

\section{OUTRAS REFERÊNCIAS}

Ministério da Educação (2011). Secretaria de Educação Básica. Passo a Passo do Programa Mais Educação. Brasília.

Ministério da Educação (2012). Caderno Pedagógico 9 - Comunicação e Uso de Mídias. Série Cadernos Pedagógicos do Programa Mais Educação. Brasília.

Ministério da Educação (2013). Censo da educação básica: 2012 - resumo técnico. - Brasília: Instituto Nacional de Estudos e Pesquisas Educacionais Anísio Teixeira.

Ministério da Educação (2013b). Instituto Nacional de Estudos e Pesquisas Educacionais Anísio Teixeira Taxa de Rendimento, Brasil.

Patrício, E. (2015, setembro). O rádio educativo na percepção de professores de educação básica - O caso rádio escolar do Programa Mais Educação. Comunicação apresentada no XXXVIII Congresso Brasileiro de Ciências da Comunicação, Rio de Janeiro.

\section{Nota BiográFicA}

Edgard Patrício é Professor do Curso de Jornalismo e do Programa de Pós-graduação em Comunicação da Universidade Federal do Ceará. É doutor em Educação Brasileira pela Universidade Federal do Ceará (UFC) e graduado em Tecnologia de Processamento de Dados. Coordena os Programas de Extensão Comunicação e Políticas Públicas e Liga Experimental de Comunicação (UFC). Participa como associado voluntário da organização não-governamental Catavento Comunicação e Educação. Membro do Conselho Gestor da Rede ANDI Brasil - Comunicação pelos Direitos da Criança e do Adolescente.

Email: edgard@ufc.br

Universidade Federal do Ceará

Av. da Universidade, 2853

Benfica,Fortaleza - CE, 60020-181, Brasil

\section{* Submetido: 14-03-2016 \\ * Aceite: 14-04-2016}

